\title{
HNF-3A, a hepatocyte-enriched transcription factor of novel structure is regulated transcriptionally
}

\author{
Eseng Lai, ${ }^{1}$ Vincent R. Prezioso, Eleanor Smith, Oksana Litvin, Robert H. Costa, ${ }^{2}$ \\ and James E. Darnell, Jr. ${ }^{3}$ \\ Laboratory of Molecular Cell Biology, Rockefeller University, New York, New York 10021 USA
}

\begin{abstract}
Hepatocyte-specific gene expression requires the interaction of many proteins with multiple binding sites in the regulatory regions. HNF-3 is a site found to be important in the maximal hepatocyte-specific expression of several genes. We find that liver nuclear extracts contain three major binding activities for this site, which we call HNF-3A, HNF-3B, and HNF-3C. Purification from rat liver nuclear extracts of HNF-3A and HNF-3C reveals that each activity corresponds to a distinct polypeptide, as determined by SDS-PAGE. Peptide sequence derived from the most abundant species, HNF-3A, was used for synthesizing probes with which to isolate a cDNA clone of this protein. The encoded protein contains 466 amino acids $(48.7 \mathrm{kD})$ and has binding properties identical to those of the purified protein. A 160-amino-acid region that does not resemble the binding domain of any known transcription factor is essential for DNA binding. The mRNA for HNF-3A is present in the rat liver but not in brain, kidney, intestine, or spleen, and the basis for this difference is cell-specific regulation of HNF-3A gene transcription.
\end{abstract}

[Key Words: Transcriptional control; hepatocyte-specific factor; HNF-3]

Received May 4, 1990; revised version accepted June 8, 1990.

Cell-specific transcriptional control exists for many specialized products of cells in all multicellular organisms. It is also the basis of the limited differences in cell type among single-cell eukaryotes (e.g., a and $\alpha$ yeast cell types). In this latter case, some of the transcription factors that act in cell-type-specific transcription exist in both cell types, but others are transcriptionally regulated factors that actually determine cell type (Nasmyth and Shore 1987; Herskowitz 1989). How do we decide the basis for the demonstrated transcriptional control (Derman et al. 1981; Powell et al. 1984) of a whole series of genes in a mammalian tissue such as the liver? Does regulated transcription in adult hepatocytes rely on one or several transcription factors that are themselves limited to hepatocytes, or are there generally distributed factors that are specially modified in the hepatocyte? To answer these questions, the identification of DNAbinding proteins that bind to sites shown to be required for hepatoma-specific expression of genes has been a fruitful initial approach (Costa et al. 1986, 1988; Cereghini et al. 1987; Courtois et al. 1987; Lichtsteiner et

Present addresses: 'Division of Endocrinology, Memorial Sloan-Kettering Cancer Center, New York, New York 10021 USA; ${ }^{2}$ Department of Biological Chemistry, University of Illinois at Chicago, Chicago, Illinois 60612 USA.

${ }^{3}$ Corresponding author. al. 1987; Monaci et al. 1988). The field has progressed to the identification of at least five nuclear protein factors detected by site-specific DNA-binding assays that appear to be limited to or at least more abundant in liver extracts than in extracts of other cell types. To know whether these factors are products of independent genes and are themselves regulated transcriptionally, it is necessary to clone the genes encoding these factors and determine their transcription patterns. The genes for two of these proteins have been characterized: C/EBP, the original leucine zipper protein (Landschulz et al. 1988) and HNF-1 (LF-B1), a protein with distant similarity to the POU homeo domain proteins (Frain et al. 1989; Baumhueter et al. 1990; Finney 1990). In this paper we report the cloning of the cDNA of a third liver-enriched transcription factor called HNF-3A. This protein may have a more limited tissue distribution than the other two factors reported previously, and the limited distribution appears to be based on transcriptional control of the HNF-3A gene. From sequence analysis and comparison with other known protein structures, the HNF-3A protein contains a DNA-binding structure unlike that of any other DNA-binding protein.

We identified this protein originally in rat liver nuclear extracts, because it binds specifically to sequences proved to be functionally important in the hepatocytespecific expression of two genes from the mouse, TTR (transthyretin) and $\alpha-1$ antitrypsin (Costa et al. 1989). 
Mutation of the HNF-3-binding site in an otherwise intact TTR promoter reduced expression of the TTR genes in HepG2 cells dramatically. Furthermore, a multimer of the HNF-3-binding site was sufficient to stimulate expression of a heterologous promoter in HepG2 cells but not in HeLa cells. The HNF-3-binding activity, itself, was highly enriched in liver cell nuclear extracts relative to those of other tissues, including spleen, kidney, brain, and intestine. All of these results suggested that proteins interacting with the HNF-3 site are essential for optimal expression of the mouse TTR and $\alpha$-1-antitrypsin genes in the liver and made any such proteins good candidates for study as a possible transcriptionally controlled transcription factor.

\section{Results}

\section{Purification and protein sequencing of HNF-3A}

HNF-3-binding activity was monitored by use of a double-stranded oligonucleotide from the mouse TTR promoter $(-111$ to -85$)$. In crude liver nuclear extracts, there appear to be three specific protein-DNA complexes detectable by gel mobility-shift assays, whereas nuclear extracts of kidney, brain, and spleen fail to form any specific complexes (Costa et al. 1989). The liver proteins responsible for the complexes can be separated partially by chromatography on heparin-agarose (Fig. 1). It is not known whether these different complexes represent binding by different modifications or proteolytic

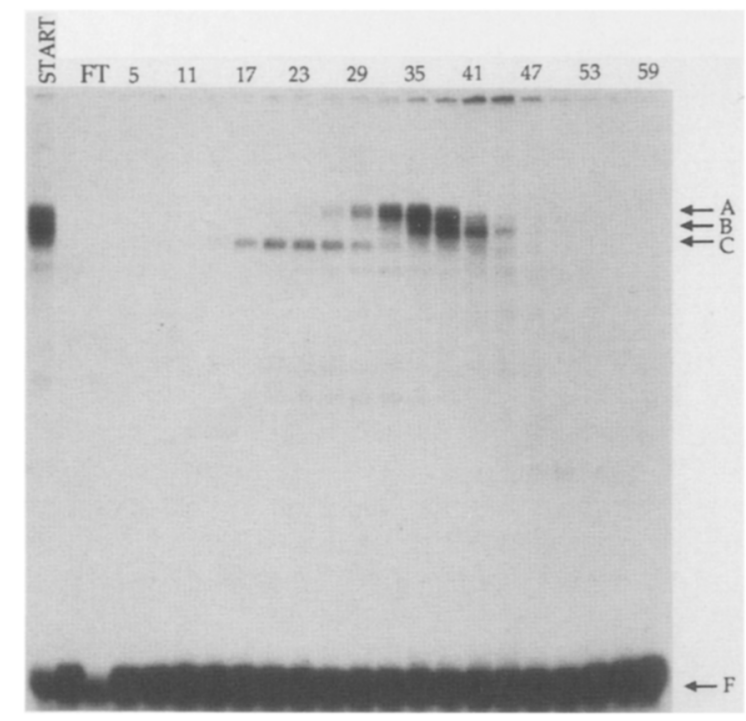

Figure 1. Three HNF-3 protein DNA complexes. A liver nuclear extract was chromatographed on a heparin-agarose column. Fractions eluted with a linear $\mathrm{NaCl}$ gradient were assayed by gel mobility shift with the strong HNF-3-binding site from the transthyretin gene as labeled probe $(-85$ to -111$)$. Approximate $\mathrm{NaCl}$ concentrations based on conductivity measurements were $0.2,0.32$, and $0.45 \mathrm{M}$ for fractions 10,30 , and 50 , respectively. Proteins in liver nuclear extract form multiple gel mobility-shift complexes. The major complexes are designated A, B, and C. Free probe is labeled F. fragments of a single protein or by different gene products. The results described below suggest that each complex represents site-specific binding to the HNF-3 oligonucleotide of different-sized molecules rather than of multimers of a single protein. Thus, we will refer to the molecules responsible for complexes $\mathrm{A}, \mathrm{B}$, and $\mathrm{C}$ as HNF-3A, HNF-3B, and HNF-3C, respectively. In our initial characterization of the HNF-3-binding activity, we separated complexes A and B from complex C to learn something about the basis of each complex and then proceeded to focus our efforts on HNF-3A.

Purification of HNF-3A to near homogeneity was achieved through five separate columns ending with three passes through the sequence-specific DNA affinity column (Table 1A). HNF-3B is also present in these preparations. Figure 2A shows an SDS-polyacrylamide gel of the proteins present through the last steps of the purification. The major band (lane 6) migrated at an apparent molecular mass of 50,000 daltons. The verification of this band as HNF-3A is shown in Figure 2, B and C. Proteins in slices of a parallel SDS-polyacrylamide gel containing the identical affinity-purified material to that shown in Figure 2A, lane 6, were extracted, renatured, and assayed for DNA-binding activity. The renatured protein from slice 3 , which contained the $50-\mathrm{kD}$ band, bound specifically to the HNF-3 oligomer and yielded a gel mobility-shift complex that is identical in mobility to that of HNF-3A in liver nuclear extracts (Fig. 2C). The smaller amount of protein of $\sim 46 \mathrm{kD}$ in slice 2 yielded a faster migrating shift complex corresponding to HNF-3B (Fig. 2C). It is difficult to distinguish between a degradation product of HNF-3A or HNF-3B and a trace amount of HNF-3C protein, which may also be present. The major contaminants at this stage, present in slice 4 , do not possess renaturable DNA-binding activity. The final affinity-purified material shown in Figure $2 B$ (which represents a sample used for amino acid sequence determination described later) contained a $50-\mathrm{kD}$ protein of HNF-3A and a small amount of a $46-\mathrm{kD}$ protein corresponding to HNF-3B.

A similar but shorter purification scheme was used for HNF-3C, which yielded a major protein of $43 \mathrm{kD}$ (Fig. $3 \mathrm{~A})$. This protein was confirmed by renaturation studies similar to those described above to be responsible for the C complex (Fig. 3B). A small amount of HNF-3A was present in the HNF-3C preparation and formed a slower migrating complex (Fig. 3B, slice 3). Thus, HNF-3A, HNF-3B, and HNF-3C each formed sequence-specific DNA-protein complexes that migrated successively faster in parallel with the decreasing polypeptide sizes of the three proteins.

Table 1 summarizes the results of each step in the purification of HNF-3A and HNF-3C. A total of $3 \mu \mathrm{g}$ of HNF-3A and $1.3 \mu \mathrm{g}$ of HNF-3C was obtained from 250 $\mathrm{mg}$ of nuclear extract. (NP-40 was added to the fractions eluted from the Sephacryl-S300 to stabilize the binding activity.) The DNA-cellulose column included in the scheme removed nuclease activity that otherwise would have destroyed the specific DNA affinity column. The preparation of HNF-3A after column chromatography 
Table 1. Purification summary of HNF-3A and HNF-3C

\begin{tabular}{|c|c|c|c|c|}
\hline & $\begin{array}{l}\text { Total protein } \\
\text { (mg) }\end{array}$ & $\begin{array}{l}\text { Activity } \\
\text { (units) }\end{array}$ & $\begin{array}{l}\text { Purification } \\
\text { (fold) }\end{array}$ & $\begin{array}{c}\text { Yield } \\
(\%)\end{array}$ \\
\hline \multicolumn{5}{|l|}{ HNF-3A } \\
\hline nuclear extract & 250 & 20,000 & & 100 \\
\hline heparin-agarose & 50 & 16,000 & 4 & 80 \\
\hline Sephacryl S-300 & 5 & 13,000 & 32 & 65 \\
\hline FPLC Mono S & 3 & 10,000 & 42 & 50 \\
\hline DNA-cellulose & 2 & 8000 & 50 & 40 \\
\hline HNF- 3 affinity $\times 3$ & 0.003 & 6000 & 25,000 & 30 \\
\hline \multicolumn{5}{|l|}{ HNF-3C } \\
\hline Nuclear extract & 250 & 8000 & & \\
\hline heparin-agarose & 24 & 7200 & 9 & 90 \\
\hline Sephacryl S-300 & 2.5 & 6000 & 72 & 75 \\
\hline FPLC Mono S & 1.6 & 5000 & 94 & 63 \\
\hline DNA-cellulose & 1 & 4200 & 133 & 53 \\
\hline HNF-3 affinity $\times 2$ & 0.0013 & 2800 & 69,200 & 36 \\
\hline
\end{tabular}

Protein was quantitated by using a colorometric method (Bio-Rad) with BSA as standard. After the affinity step, quantitation was by silver and Coomassie blue stain. DNA-binding activity was determined with gel mobility-shift assays. One unit is defined as the activity that binds $0.1 \mathrm{ng}$ of probe under standard assay conditions. Because the binding is performed in the presence of nonspecific competitor prior to the affinity column, the quantitation is not directly comparable before and after the affinity column. As defined, the values probably underestimate activity in the nuclear extract and overestimate both the final yield and fold purification.

was estimated to be $\sim 75 \%$ pure (see Fig. $2 \mathrm{~B}$ ), whereas the sample of HNF-3C was $\sim 90 \%$ pure. To obtain pure protein for sequencing, each sample was applied to an SDS-polyacrylamide gel and electroblotted to a PVDF membrane. The membrane was stained with Coomassie Blue, and either the $50-\mathrm{kD}$ or the $43-\mathrm{kD}$ band was excised and submitted for sequence analysis. Two attempts for each preparation yielded no sequence information, presumably due to blockage of the amino terminus of each protein.

At this point, we decided to focus on the more abundant and larger HNF-3A. We sought to generate and purify peptide fragments of HNF-3A for sequencing. Ten micrograms of purified protein was obtained from 800 mg of nuclear extract after column chromatography. An SDS-polyacrylamide gel was again used to isolate the $50-\mathrm{kD}$ protein. After electroelution and removal of SDS, the protein was digested with endoproteinase lys-C, which cleaves specifically at lysine residues. The peptides were then separated by reverse-phase HPLC on a C-18 column. Four peaks were submitted for sequencing. Two peptide samples yielded unambiguous sequences, which allowed the design of oligonucleotide probes 157 and 144 for screening a rat liver cDNA library (Fig. 4).

\section{Cloning and sequencing of HNF-3A}

From $1,000,000 \lambda$ phage recombinants, $\sim 50$ positive clones were isolated with probe 144 . Because this probe contained inosine residues, we expected to identify false-positive clones. Therefore, we screened these clones with probe 157 and found that only one hybridized to both probes. Sequence of this clone showed that it encoded both peptides derived from the purified protein. Subsequently, this clone was used to screen at high stringency another $1,000,000$ recombinants from the same library. An additional nine independent clones were identified. The longest recombinant, $\mathrm{H} 3$, contained a $2.2-\mathrm{kb}$ insert and was used for most of the subsequent analyses. The sequence of $\mathrm{H} 3$, shown in Figure 5, contains the entire coding sequence of HNF-3A but is missing a short stretch of the 3 '-untranslated region. An open reading frame encoding a protein of 466 amino acids begins at base 58 preceded by a sequence that fits well with the consensus for translation initiation (Kozak 1986). The calculated molecular weight of 48,700 daltons agrees well with the molecular mass estimate of $50 \mathrm{kD}$ based on SDS-polyacrylamide gel analysis of the purified protein, and the protein product derived from this cDNA by in vitro transcription and translation has a mobility on SDS-polyacrylamide gels identical to that of the purified protein.

Because the sequence contains multiple methionines at the amino-terminal end, we determined whether the full-length protein resulted from translation initiation at either the first or second methionine. RNA for translation was produced by SP6 or T7 polymerase by copying the entire H3 sequence. Reticulocyte extracts produced the full-length $50-\mathrm{kD}$ band from the full-length RNA (Fig. 6A, lane 1). A deletion construct lacking the first 98 nucleotides, just beyond the second in-frame AUG, was then used to generate RNA for in vitro translation. The translation product from the deletion (shown in lane 2) was slightly but distinctly smaller than the full-length protein. Therefore, the preferred initiator AUG appeared to be removed by the deletion, resulting in initiation at a downstream site in the reticulocyte lysate.

DNA binding of in vitro-translated HNF-3A and delineation of residues required for binding

Verification that the H3 clone encoded the HNF-3A DNA-binding activity was obtained in several ways. 


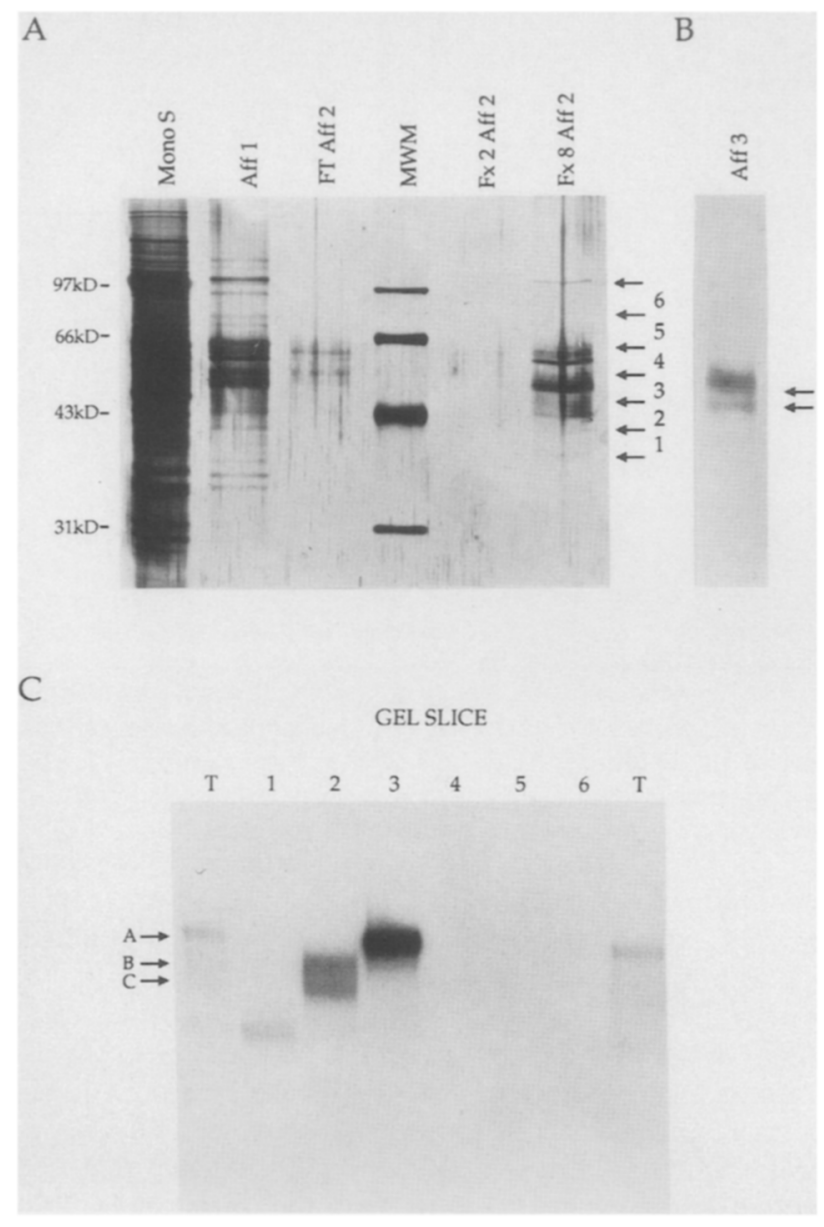

Figure 2. Renaturation of HNF-3A activity. (A) A silverstained SDS-polyacrylamide gel of samples from the later stages of the purification of HNF-3A. (Lane 1) Mono S pool (Mono S); (lane 2) first affinity pool (Aff 1); (lane 3) second affinity flowthrough (FT Aff 2); (lane 4) molecular weight markers (MWM); (lane 5) second affinity column, fraction 2 (Fx 2 Aff 2); (lane 6) second affinity column, fraction 8 (Fx 8 Aff 2), which contained the peak binding activity. Arrows indicate the position of cuts made in a parallel gel of fraction 8 to yield six gel slices. Protein from these gel slices was eluted, renatured, and assayed for binding activity, as shown in $C$. (B) A sample of the material pooled from a third-pass HNF-3 affinity column showing the major $50-\mathrm{kD}$ protein band and a minor $46-\mathrm{kD}$ protein. $(C)$ Autoradiograph of a gel mobility-shift assay with renatured samples from $A$, gel slices $1-6$. (Lane $T$ ) Total sample from affinity fraction 8 , diluted $1: 50$. Renaturation recovery is estimated at $\sim 20 \%$. Slice 3 , corresponding to the $50-\mathrm{kD}$ protein region, yielded a complex identical to complex $A$, the major complex of the starting sample. Slice 2 contained a $46-\mathrm{kD}$ protein that yielded a faster migrating complex equivalent to HNF-3B in Fig. 1. Slice 2 also contained a trace of activity corresponding to complex $\mathrm{C}$.

First, the sequence of $\mathrm{H} 3$ contains both sequenced peptides derived from purified HNF-3A protein (Fig. 5). Second, we demonstrated that the protein product of $\mathrm{H} 3$ binds specifically to the HNF-3 site of the TTR promoter. In vitro protein products translated from SP6 or T7 RNA polymerase transcripts bound to the HNF-3binding site, as tested by gel mobility-retardation assays

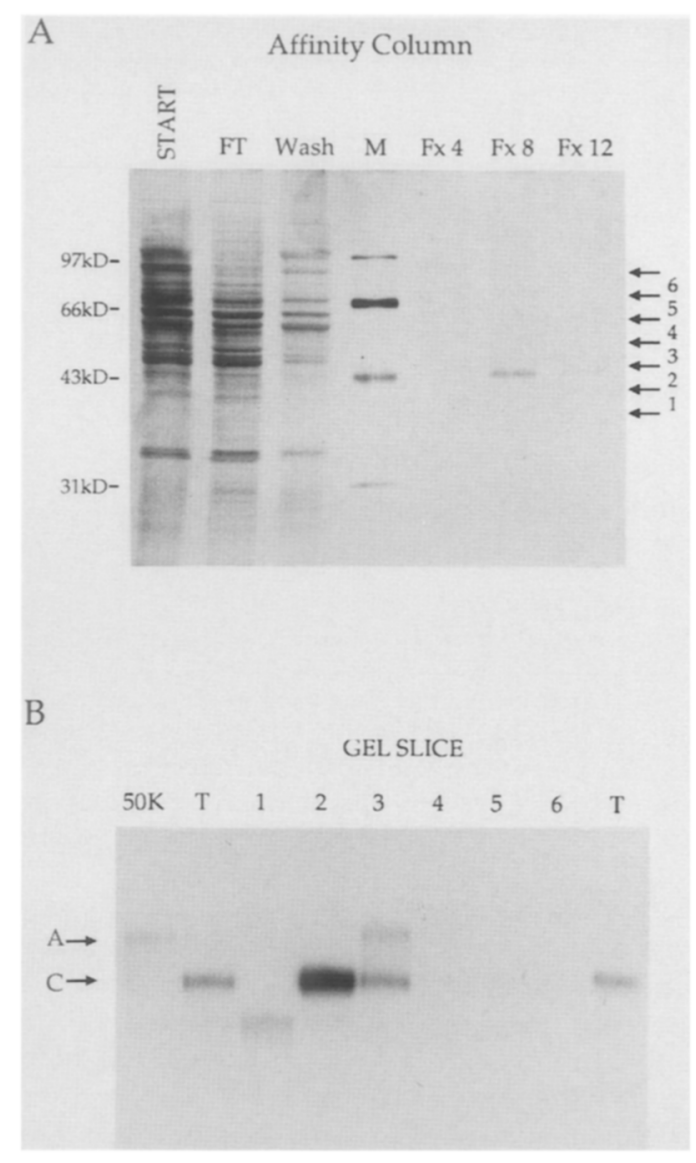

Figure 3. Renaturation of HNF-3C activity. (A) A silverstained gel containing samples of complex $\mathrm{C}$ (see Fig. 1), bound and eluted twice from a specific oligonucleotide affinity column. (Lane 1) Starting material loaded onto column (START); (lane 2) flowthrough fraction (FT); (lane 3) $0.15 \mathrm{M}$ $\mathrm{NaCl}$ wash (Wash); (lane 4) markers (M); (lane 5) fraction 4 (Fx 4); (lane 6) fraction 8 (Fx 8); (lane 7) fraction 12 (Fx 12). Fraction 8 contains the peak binding activity. Arrows indicate the position of cuts made to a parallel gel lane with fraction 8 to yield six gel slices. Protein from these gel slices was eluted, renatured, and assayed for binding activity, as shown in $B .(B)$ An autoradiograph of a gel mobility-shift assay with renatured samples from gel slices $1-6$. (Lane $T$ ) Total sample from fraction 8 , diluted $1: 50$. Slice 3 contained the major $43-\mathrm{kD}$ protein and yielded a complex identical to complex $C$, whereas slice 4 contained a small amount of protein yielding complex A. (50K) Sample from fraction 8 of HNF-3A (see Fig. 2), which yielded predominantly complex A.

with a double-stranded oligomer of the HNF-3-binding site $(-107$ to -92 ; Fig. $6 \mathrm{~B})$. The specific DNA-protein complex formed with in vitro-produced protein migrated at the same rate as that of the complex with partially purified rat HNF-3A protein. The in vitro-translated product was prevented from forming a complex only by an oligonucleotide representing the HNF-3-binding site (Fig. 6B, lane 2). The identity of in vitro-translated product of the $\mathrm{H} 3$ clone with the liver protein HNF-3A was demonstrated further by a footprint assay (Fig. 6C). The binding of the protein product of the $\mathrm{H} 3$ clone to a fragment of the TTR promoter protected the nucleotides 


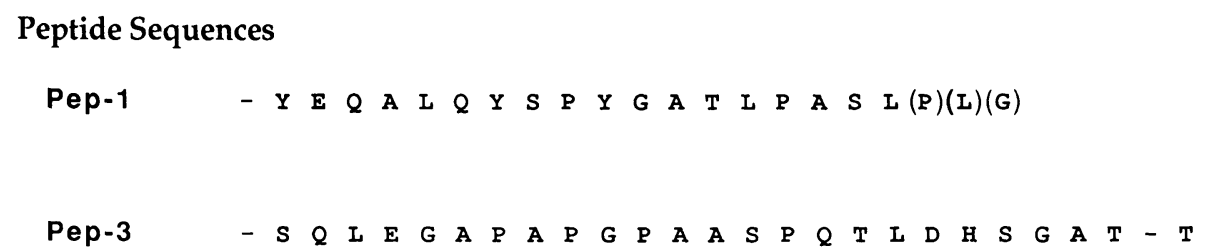

Oligonucleotide Probes

Figure 4. Amino acid sequence of peptides derived from purified HNF-3A and the DNA oligonucleotides synthesized as probes. Parts of the sequence in parentheses were of lower certainty due to decreasing yields and increasing background. Probe 157, a 47-mer from Pep-1, was designed based on codon-usage tables (Lathe 1985), whereas probe 144, a 56-mer from Pep-3, was designed based on both codon usage and the use of inosines at positions of greatest potential ambiguity (Takahashi et al. 1985).

from -97 to -107 upstream of the cap site from chemical cleavage (Fig. 6C). This footprint exactly matches that of the partially purified rat liver HNF-3 determined previously (Costa et al. 1989). The TTR genomic fragment used in this assay also contains sites for HNF-1, C/EBP, and HNF-4, none of which were protected by either the purified protein or the in vitro translation product, emphasizing that HNF-3A binds to a distinct site. All of these data confirm that the $\mathrm{H} 3$ clone encodes the sequence-specific DNA-binding protein HNF-3A, which we have purified.

The portion of the HNF-3A protein that is important for DNA binding was tested by transcription and translation of RNA that represented the full-length protein or subsections of the protein. Figure 7 shows the analysis of proteins made from a series of $3^{\prime}$ deletions of the $\mathrm{H} 3$ clone. Figure 7A shows the products of in vitro translation after electrophoresis through an SDS-polyacrylamide gel. The total translation products were assayed for site-specific DNA-binding activity as shown in Figure 7B. Removal of up to 178 amino acids from the carboxy-terminal end did not affect site-specific DNAbinding activity (PvuII and deletion 7; a nonspecific band between arrows 1 and 2 arises from reticulocyte proteins). Deletion of an additional 38 amino acids effectively abolishes the specific binding activity (deletion 14). These experiments plus $5^{\prime}$ deletions that were translated in vitro (data not shown) limit the DNAbinding region to amino acids 124-288 and show that amino acids 251-288 contain an essential part of the binding domain (Fig. 5, bottom).

Comparisons of the HNF-3A sequence with those proteins in the Genbank data base revealed no homology to any known DNA-binding proteins. Thus, HNF-3A contains a novel DNA-binding structure that remains to be characterized fully. A distant but possibly interesting homology was noted with the Drosophila Notch protein. The sequence of Notch predicts a large transmembrane protein with multiple epidermal growth factor (EGF)like repeats in the extracellular domain. The region of homology with HNF-3A extends from nucleotide res- idue 2230 to 2600 , which encodes the intracellular domain of the protein. Recently, two yeast regulatory proteins, SW114 and SW116, have been found to exhibit distant homology to Notch but in yet another region of this protein's intracellular domain. At this point, it is only speculation to suggest any related effector function between any of these evolutionarily distant proteins.

\section{Limited distribution of HNF-3A is based on transcriptional control of the gene}

Because the presence of HNF-3A-binding activity was not detected in brain, spleen, or kidney extracts but was restricted to liver extracts, we next sought to establish the level of such regulation. The steady-state levels of HNF-3A mRNA in several rat tissues were tested by Northern blot analysis. Two predominant RNA species were found in liver with sizes of 2 and $2.2 \mathrm{~kb}$. A smaller amount of the same mRNA was present in small intestine. These mRNAs were not detected in spleen, brain, and kidney RNA (Fig. 8A). We do not yet know the basis for the expression of the two different mRNA species.

Run-on transcription rates determined from isolated nuclei from liver, brain, and kidney showed that the transcription rate is at least 20 -fold greater in liver than in either of the other tissues studied (Fig. 8B). These data show that the HNF-3A gene, itself, is expressed in a tissue-specific manner and that this expression is regulated at the level of transcription.

\section{Discussion}

The initial issues to settle in the study of hepatocytespecific transcription were (1) the number of different regulatory proteins involved and (2) whether any of these proteins were found only (or mainly) in hepatocytes. We now have at least some preliminary answers to these questions. The regulatory regions of several genes have been explored thoroughly, and each shows multiple sites of DNA-protein interaction required for hepatocyte-specific expression; several of these proteins give evidence of being present mainly in the liver of 
ACC CGC CCG TCG TTC CGC ACA GGG TTG GAT AGT TGT GTC GGC CAG GGT GGC TCC AGG ATG TTA GGG ACT GTG AAG ATG $M \quad L \quad G \quad T \quad V \quad K \quad M$

GAA GGG CAT GAG AGC AAC GAC TGG AAC AGC TAC TAC GCG GAC ACG CAG GAG GCC TAC TCC TCT GTC CCG GTC AGC AAC

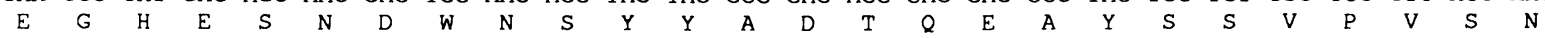

ATG AAC TCC GGC CTG GGC TCC ATG AAC TCC ATG AAC ACC TAC ATG ACC ATG AAC ACC ATG ACC ACG AGC GGC AAC ATG $\begin{array}{llllllllllllllllllllllllllllll}M & N & S & G & L & G & S & M & N & S & M & N & T & Y & M & T & M & N & T & M & T & T & S & G & N & M\end{array}$ ACC CCG GCT TCC TTC AAC ATG TCC TAC GCC AAC CCG GGC TTA GGG GCC GGC CTG AGT CCG GGT GCT GTG GCC GGC ATG $\begin{array}{lllllllllllllllllllllllllll}T & P & A & S & F & N & M & S & Y & A & N & P & G & \text { L } & G & A & G & L & S & P & G & A & V & A & G & M\end{array}$

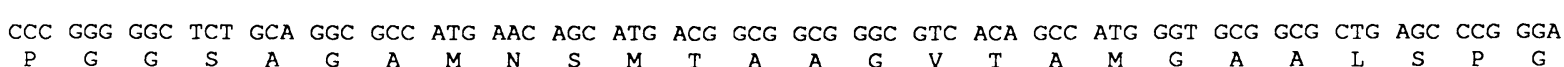
GGC ATG GGC TCC ATG GGC GCG CAG CCC GCG GCC TCT ATG AAC GGC CTG GGT CCC TAC GCT GCC GCC ATG AAC CCG TGC

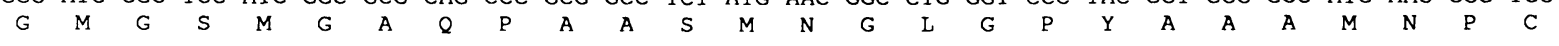
ATG AGT CCC ATG GCG TAC GCT CCG TCC AAT CTG GGC CGC AGC CGC GCG GGG GGC GGC GGC GAC GCC AAG ACG TTC AAG $\begin{array}{llllllllllllllllllllllllllllll}M & S & P & M & A & Y & A & P & S & N & L & G & R & S & R & A & G & G & G & G & D & A & K & T & F & K\end{array}$ CGC AGT TAC CCT CAC GCC AAG CCG CCC TAC TCC TAC ATC TCG CTC ATC ACC ATG GCC ATC CAG CAG GCG CCC AGC AAG

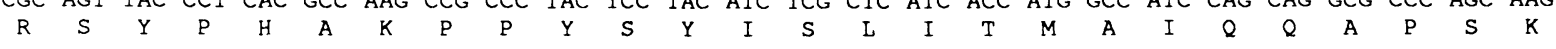
ATG CTC ACG CTG AGC GAA ATC TAC CAG TGG ATC ATG GAC CTC TTC CCC TAT TAC CGT CAG Aac CAg CAG CGC TGG CAG $\begin{array}{llllllllllllllllllllllllll}M & L & T & L & S & E & I & Y & Q & W & I & M & D & L & F & P & Y & Y & R & Q & N & Q & Q & R & W & Q\end{array}$

AAC TCC ATT CGC CAC TCA CTG TCT TTC AAC GCT TGT TTC GTC AAG GTG GCG CGA TCC CCG GAC AAG CCG GGC AAG GGC $\begin{array}{lllllllllllllllllllllllllllll}\mathrm{N} & \mathrm{S} & \mathrm{I} & \mathrm{R} & \mathrm{H} & \mathrm{S} & \mathrm{L} & \mathrm{S} & \mathrm{F} & \mathrm{N} & \mathrm{A} & \mathrm{C} & \mathrm{F} & \mathrm{V} & \mathrm{K} & \mathrm{V} & \mathrm{A} & \mathrm{R} & \mathrm{S} & \mathrm{P} & \mathrm{D} & \mathrm{K} & \mathrm{P} & \mathrm{G} & \mathrm{K} & \mathrm{G}\end{array}$ TCC TAC TGG ACG CTG CAC CCG GAC TCC GGC AAC ATG TTC GAG AAC GGC TGC TAC TTG CGC CGT CAA AAG CGC TTC AAG TGT GAG AAG CAG CCG GGG GCC GGA GGT GGG AGT GGG GGC GGC GGC TCC AAG GGG GTC CCA GAA AAC CGC AAA GAC CCC

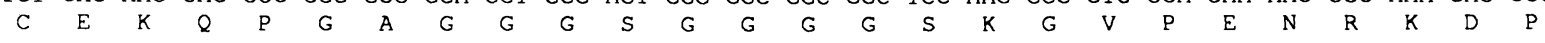
TCA GGC CCG GTT AAC CCC AGT GCC GAA TCA CCC ATT CAT CGG GGT GTG CAC GGA AAG GCT AGC CAG CTA GAG GGC GCG

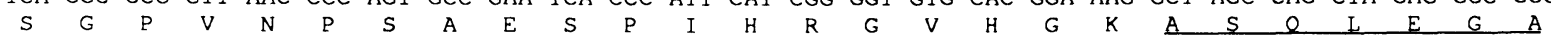

CCG GCC CCC GGG CCC GCC GCC AGC CCC CAG ACT CTG GAC CAC AGT GGG GCC ACG GCG ACA GGG GGC GGT TCG GAG TTG

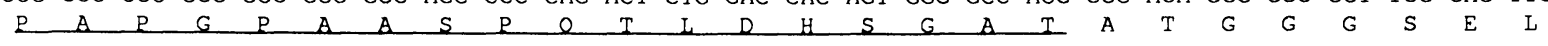
AAg TCT CCA GCT TCT TCA TCT GCG CCC CCC ATA AGC TCC GGG CCA GGG GGC TGG ATC TGT ACC CCC CTC TCA CCG ACA

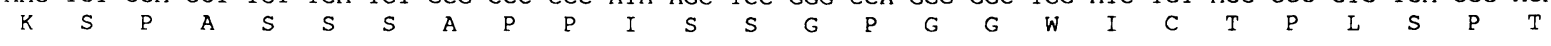
TGG CTT GCC CCC CAC GAA TCT CAG CTG CAC CTG AAA GGG GCC CCC CAC TAC TCC TTT AAC CAC CCC TTC TCC ATC AAC

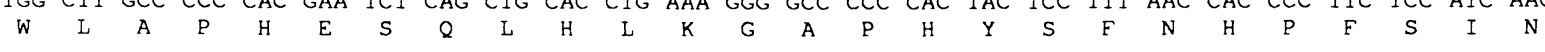
AAC CTC ATG TCC TCC TCG GAG CAG CAG CAC AAG CTG GAC TTC AAG GCA TAT GAG CAG GCA CTG CAG TAC TCT CCT TAC

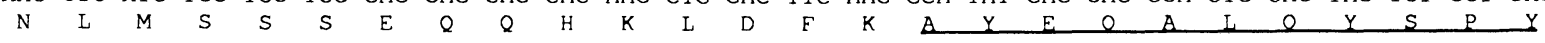
GGC GCC ACC TTG CCC GCC AGT CTG CCC CTT GGC GGC GCC TCA GTG GCC ACG AGG AGC CCC ATC GAG CCC TCA GCC CTG $\begin{array}{llllllllllllllllllllllllll}G & A & T & L & P & A & S & L & P & L & G & G & A & S & V & A & T & R & S & P & I & E & P & S & A & L\end{array}$ GAG CCG GCC TAC TAC CAA GGT GTG TAT TCC AGA CCC GTG CTA AAT ACT TCC TAG CTC CCA GAA CTG AGG GTT TGT CTG E $\begin{array}{lllllllllllllllllll}P & A & Y & Y & Q & G & V & Y & S & R & P & V & L & N & T & S\end{array}$

CATGGCCAACCTGGTATGGTAGCAGGAGAGAAAAACCAACAGTAAACACACACACACACAGAGTCACACACACATACAGAGTCACACACACAGACACACACAC ACACTGACACACTCACACTGACACACTCACAGAGTCACACACACATACAGAGATATCTGCAAATACAGCTCAGGGTTTGAAAGAATAATATATAACCGAAGAC TAAGAAAGTGTGTGAGCCCAGTATGCATTCACAGAACTCCAGGTATTTTGTGGGAACTGAGTGACTTTGGAAGTGAAAGCAGATGCAGCAGCATTGGAAAGTA GCCCAGAACTCCACACTGGCTGAAACTTGGATTTTATTCACCAAGCTGCATGTCCTTGGTTCTGGAAAGCAATTTAGTTCTTGTTCTTCTTTCGGTGAGCATG AAACTGGACTGCTCAGGAGTATGGAAACTGTAAAAACTTCAGAGTCAGCAAAAGGAAATCATGACTTCACTTTAGCAGAGGAGATTTTAAAACTTCTGACTTT TGAGACCACATCTTAATAACTACATAAGAAACCCTGAGTTATGATGACCCAGCTAAACAAGTTCCCCAAACACT AGCATCATCAGCTGCGACAGTGTTCACTA ACCCTTTGCTTGAAATTGATGTCACAAGCTTCAGGCAGGTACCCTGTCTGTCCTGTCCCAGTGCTAGACAGCCTGATGTGATGGAATTC

AUG

UAG

aa 1 124

Figure 5. Nucleic acid sequence of $\mathrm{H} 3 \mathrm{cDNA}$ encoding HNF-3A. The predicted amino acid sequence of the protein is shown below the nucleotide sequence beginning with the initiator AUG at base 58 . The two peptide sequences matching that obtained by direct protein sequencing of purified HNF-3A peptides are underlined. Below the sequence is a diagram of the residues found by deletion analysis to be important for DNA binding (see Fig. 7). 


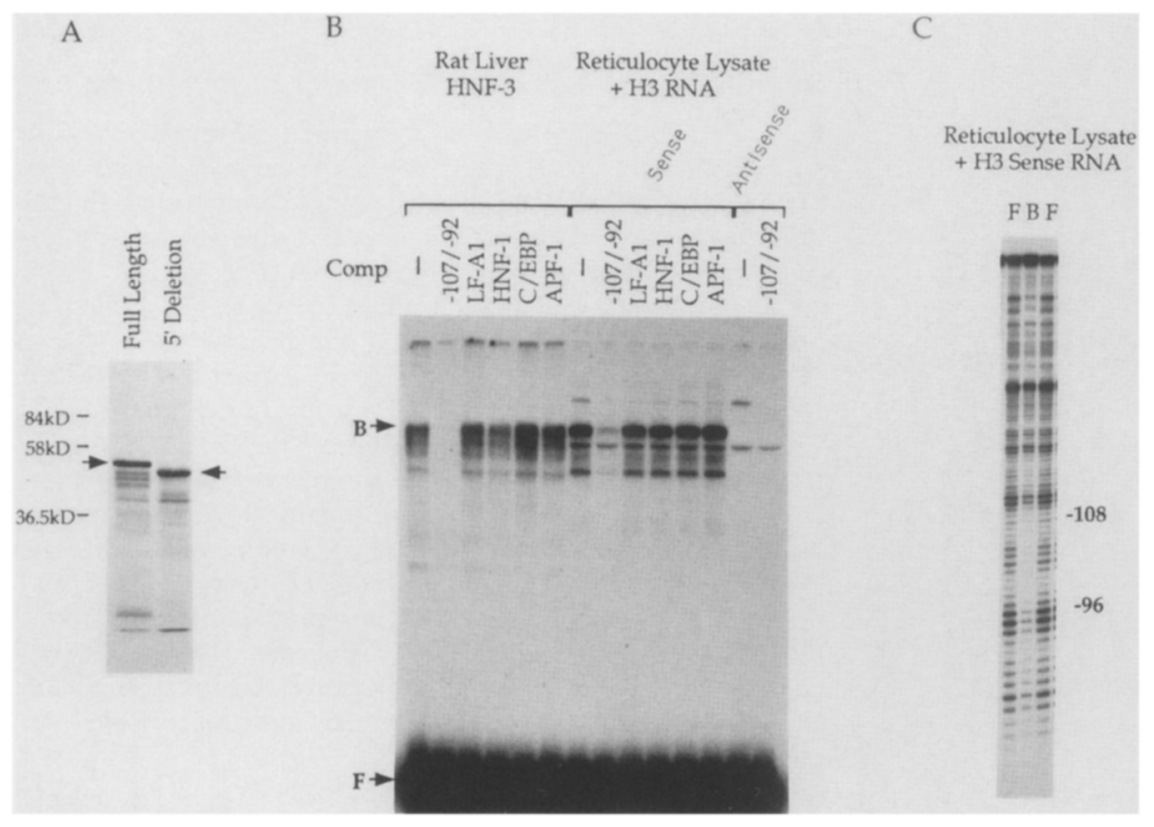

Figure 6. The $\mathrm{H} 3$ clone encodes a protein with the DNA-binding properties of HNF-3A. (A) Deletion of nucleotides 1-97 shortened the translated protein. (Lane 1) Autoradiograph of the translated product of the full-length H3 DNA analyzed by SDSPAGE on a $9 \%$ acrylamide gel. This protein has an apparent molecular mass of 50,000 daltons, which is identical to that of the purified protein. (Lane 2) The product of a 5 ' deletion of $\mathrm{H3}$, which removes nucleotides 1-97, including the first two AUGs of the open reading frame. This protein is shortened from the intact protein by $\sim 3.5$ $\mathrm{kD}$, resulting from initiation at a downstream AUG, probably the next one beginning at residue 34 . $(B)$ Comparison of the binding specificity of the translated product of H3 DNA with that of partially purified HNF-3A by gel mobility-shift analysis. One hundred picograms of partially purified HNF-3A or $1 \mu \mathrm{l}$ of reticulocyte lysate containing the translation product of H3 was assayed for DNA binding, as described previously (Kovesdi et al. 1986). Binding reactions were performed in the presence of one of the following double-stranded oligonucleotides. (- Control with no oligonucleotide; $(-107 /-92)$ the HNF-3-binding site from mouse TTR promoter; (LF-A1) the binding site from the human $\alpha$-1-antitrypsin promoter, which shares a 7 of 12 -nucleotide sequence identity to the HNF-3-binding site (DeSimone et al. 1988); (HNF-1) the binding site from the fibrinogen promoter (Courtois et al. 1987); and (APF-1) the binding site from the human apolipoprotein CIII promoter (Reue et al. 1988). Linearized plasmids were used as templates for transcription with T7 or SP6 RNA polymerase (Melton et al. 1984). In vitro translation was performed by use of nuclease-treated rabbit reticulocyte lysate (Promega) according to the manufacturer's protocol. ${ }^{35} \mathrm{~S}$ ]-methionine (translation grade) was purchased from Amersham. The dried gel was exposed directly to X-ray film at room temperature. $(C) \mathrm{Cu}$-phenanthroline footprint of in vitro-translated HNF-3A on the promoter $(-202 /-70)$ of the mouse TTR gene. The products of partial cleavage by Cuphenanthroline of free probe $(\mathrm{F})$ and probe bound $(\mathrm{B})$ to protein translated in reticulocyte lysates from the $\mathrm{H} 3$ clone are shown. Between the positions of bases -96 and -108 , the cleavage of the bound probe is markedly inhibited.

adult animals (for review, see Johnson 1990). Two of these proteins have been cloned, and each is part of a multigene family. HNF-1 (LF-B1) is a homeo domain protein (Frain et al. 1989; Baumhueter et al. 1990; Finney 1990), and C/EBP is the original member of the leucine zipper family of proteins (Landschulz et al. 1988). This report adds a third cloned cDNA encoding a protein found mainly or only in the liver and interacting with positive cis-acting regulatory regions of several genes expressed in hepatocytes. The newly cloned gene HNF-3A encodes a novel protein whose sequence is clearly not related to either HNF-1 or C/EBP. Even within the $\sim 160$ amino acids that direct DNA binding (124-288), there is no resemblance to well-recognized DNA-binding motifs. There are many proline and glycine residues that would limit $\alpha$-helix formation to relatively short regions; thus, HNF-3A is a candidate for a new class of site-specific DNA-binding proteins.

As tested by gel mobility-shift analysis with a specific oligonucleotide site, the HNF-3A protein is the most abundant liver protein that recognizes the characterized HNF-3 site. In separate experiments, using a new in vivo footprint method (J. Mirkovitch and J.E. Darnell, in prep.), we have found that the HNF-3 site in TTR gene is indeed occupied specifically in liver nuclei. Furthermore, this site was shown earlier to be critical and sufficient for activation of the globin promoter in transfected
HepG2 cells. However, the role of HNF-3A as a positiveacting protein has not been proved. Additional work will be required to determine whether HNF-3A can activate transcription or whether the other HNF-3-binding activities, HNF-3B or HNF-3C, represent distinct proteins with positive-acting function. In this regard we note that two mRNA bands are observed in Northern blot analysis, and recently, we have detected a clone of a related but nonidentical sequence present in both rats and mice, indicating the existence of a second protein similar to HNF-3A (E. Lai, V.R. Prezioso, and J.E. Darnell, unpubl.).

Whatever the outcome of detailed mechanisms of transcriptional regulation involving the HNF-3-binding site, the HNF-3A protein represents a site-specific DNA-binding protein whose cell distribution in animals is highly specific. Northern blot analysis failed to detect the mRNA for this protein in any tissue other than liver, and this limited distribution is based on transcriptional regulation. This latter result is most important because a major goal of this work is to discover how, in the course of development, liver-specific transcription is initiated and maintained. We showed previously that the gene encoding C/EBP was transcriptionally controlled (Xanthopoulos et al. 1989) and have recently also shown that HNF-4 is transcriptionally controlled (K. Xanthopoulos et al., in prep.). Thus, the present findings with the HNF-3A cDNA provide strong evidence that a bat- 


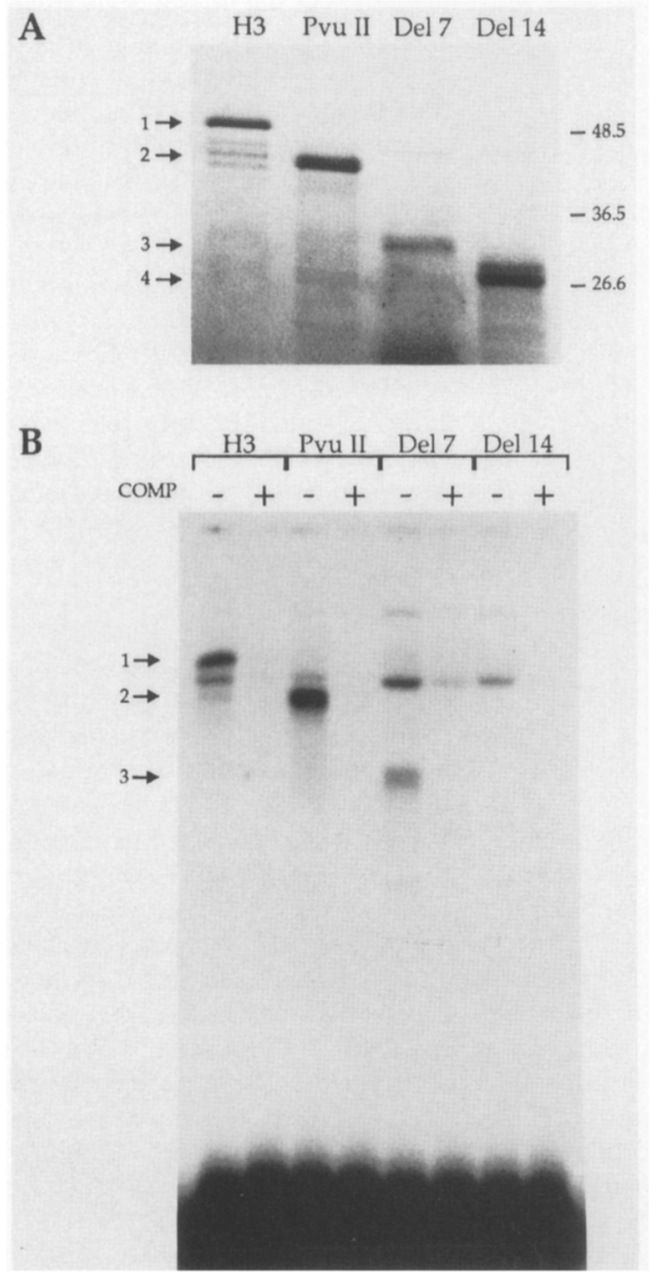

Figure 7. DNA-binding domain is disrupted by a 38-aminoacid deletion between residues 253 and 291. (A) Analysis of in vitro translation products from $3^{\prime}$ deletion constructs of HNF-3A by SDS-PAGE. The arrows indicate the positions of the major product translated in the reticulocyte lysate. $(B)$ Binding of these products to the HNF-3-binding site by the gel mobility-shift assay. The arrows indicate the position of the protein-DNA complex observed with the largest three protein products. Deletions of the $3^{\prime}$ end of the $\mathrm{H} 3$ clone were generated by restriction cleavage or by exonuclease III/mung bean nuclease digestion by use of the kit from Stratagene. The positions of the 3 '-end base for each deletion are as follows: PvuII (1194), deletion 7 (923), deletion 14 (807). In vitro translation and analysis of the products were performed as described in the legend to Fig. 2. Twice as much reticulocyte lysate was assayed for deletion 7 compared to the others to compensate for variation in translation efficiency in this preparation. The band between complexes 1 and 2 arises from reticulocyte proteins.

tery of nuclear site-specific DNA-binding proteins are under transcriptional control in hepatocytes. A search for proteins that coordinately regulate the transcription of HNF-3, HNF-4, and C/EBP can now be made with some confidence. Such studies should take us closer to the antecedent factors and signals that control hepatocyte determination and differentiation.

\section{Materials and methods}

Purification of HNF-3A

Rat liver nuclei were isolated by pelleting through a sucrose cushion (Gorski et al. 1986) and extracted with buffer containing $0.4 \mathrm{M} \mathrm{KCl}$. After removal of the chromatin and other insoluble material by centrifugation, the supernatant was collected and frozen in liquid $\mathrm{N}_{2}$. Extract from 32 rat livers ( 60-70 ml) was thawed and diluted with HGDE buffer [20 mM HEPES (pH 8.0), 10\% glycerol, $1 \mathrm{~mm}$ dithiothreitol, $0.1 \mathrm{~mm}$ EDTA] to adjust the conductivity of the extract to $300 \mu \mathrm{S}$. All subsequent steps were performed at $4^{\circ} \mathrm{C}$. The diluted sample was held for $20 \mathrm{~min}$ and centrifuged at $10,000 \mathrm{~g}$ for $20 \mathrm{~min}$ to remove any precipitate. The supernatant was applied to a $60-\mathrm{ml}$ heparin-agarose column (Sigma). Protein was eluted with a linear $\mathrm{NaCl}$ gradient $(0.2-0.8 \mathrm{M})$. Fractions producing the slowest migrating complex (complex A, Fig. 1) were pooled, and the protein was concentrated by precipitation with $50 \%$ ammonium sulfate. This sample was applied to a $300-\mathrm{ml}$ Sephacryl-S300 gel filtration column (Pharmacia), equilibrated, and eluted with HGDE $/ 0.2 \mathrm{M} \mathrm{KCl}$. Active fractions were pooled, applied to a Mono S FPLC column $(0.5 \times 5 \mathrm{~cm})$, and eluted with a salt gradient of $\mathrm{KCl}$. Fractions containing between 0.3 and $0.4 \mathrm{M}$ $\mathrm{KCl}$ were adjusted to $0.15 \mathrm{M} \mathrm{KCl}$ and applied to a 2-ml DNAcellulose column. The binding activity was eluted $(0.25-0.4 \mathrm{M}$ $\mathrm{KCl}$ ), diluted to $0.15 \mathrm{M} \mathrm{KCl}$, and applied to a 1-ml affinity resin containing multimers of the double-stranded binding site for HNF-3 coupled to Sepharose (Kadonaga and Tjian 1986). The binding site oligonucleotide used was

\section{TCGAGTTGACTAAGTCAATAATCAGAATCAG CAACTGATTCAGTTATTAGTCTTAGTCAGCT}

Active fractions were eluted between 0.25 and $0.4 \mathrm{M} \mathrm{NaCl}$. This material was passed over the affinity column two additional times. Final purification for amino-terminal sequencing was

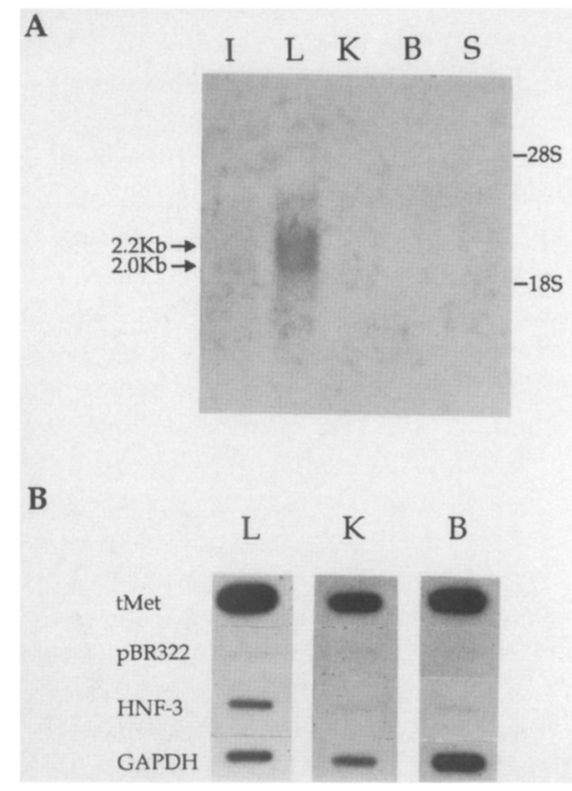

Figure 8. Cell-specific expression of HNF-3A. $(A)$ Northern analysis of mRNA from several different tissues probed with a fragment of HNF-3A cDNA. (I) Intestine; (L) liver; (K) kidney; (B) brain; (S) spleen. (B) Run-on transcription rate from nuclei isolated from three tissues. Run-on transcription rates were determined in isolated nuclei from rat tissues, as described (Xanthopoulos et al. 1989). 
achieved by applying the sample to an SDS-polyacrylamide gel and electroblotting to PVDF membrane (Immobilon, Millipore). The membrane was stained with Coomassie Blue, and the protein band of $50 \mathrm{kD}$ was excised.

\section{Purification of HNF-3C}

The purification was essentially as described for HNF-3A, except that the activity monitored was gel mobility-shift complex $\mathrm{C}$ (Fig. 1). Fractions between 0.25 and $0.3 \mathrm{M} \mathrm{KCl}$ were collected from the Mono S column. Only two passes over the affinity column were performed. The protein band of $43 \mathrm{kD}$ was isolated on Immobilon.

\section{Preparation and separation of peptides of HNF-3A}

Three separate preparations of HNF-3A, as described above, were pooled. The NP-40 detergent in the sample from the affinity column was exchanged with octyl glucoside on a Mono $S$ column. This enabled the sample to be concentrated by ultrafiltration (Centricon 10, Amicon) and then applied to an SDSpolyacrylamide gel. The $50-\mathrm{kD}$ band was visualized with $\mathrm{KCl}$, excised, and electroeluted from the gel. The sample was lyophilized and dissolved in $100 \mu \mathrm{l}$ of water. The salt concentration in the sample was reduced 20 -fold by ultrafiltration. The sample was lyophilized, and the SDS was removed by ion pair extraction. The protein preparation was digested in $70 \mu \mathrm{l}$ of $0.1 \mathrm{M}$ $\mathrm{NH}_{4} \mathrm{HCO}_{3}$ with $500 \mathrm{ng}$ of Endoproteinase Lys-C (Boehringer Mannheim) in two aliquots for $18 \mathrm{hr}$ at $37^{\circ} \mathrm{C}$. Urea was added to $3.5 \mathrm{M}$, an additional $200 \mathrm{ng}$ of enzyme was added, and the sample was incubated for $4 \mathrm{hr}$ at $37^{\circ} \mathrm{C}$.

Mercaptoethanol was added to $5 \mathrm{~mm}$, and after $10 \mathrm{~min}$ at $37^{\circ} \mathrm{C}, 10 \mu \mathrm{l}$ of $1 \%$ trifluoroacetic acid (TFA) was added. The sample was loaded onto a Vydac C-18 column $(2.1 \mathrm{~mm} \times 5$ $\mathrm{cm})$. Peptides were separated by using a gradient of acetonitrile in $0.1 \%$ TFA. Pooled fractions of three peaks were concentrated and sequenced. One complex peak was reapplied to the column and separated with a shallower gradient. The major peak of this second column was submitted for sequencing.

\section{Isolation of a cDNA clone of HNF-3A}

The $\mathrm{H} 3$ clone was obtained by screening a random and oligo(dT)-primed rat liver cDNA library (Stratagene). Hybridization and washes were performed with standard protocols using two oligonucleotide probes, 144 and 157 . Hybridization with probe 144 was in $5 \times$ SSPE, $0.1 \%$ SDS at $45^{\circ} \mathrm{C}$, and washes were in $1 \times \mathrm{SSPE}$ at $55^{\circ} \mathrm{C}$. Approximately 50 positive phage were purified, and the cDNA inserts were excised as plasmids $(\lambda$ ZAP protocol, Stratagene). Southern hybridization to the plasmid DNA digested with EcoRI was performed with probe 157 on Zeta-Probe filters (Bio-Rad). Only one clone, labeled F25, hybridized to probe 157 (wash $1 \times \operatorname{SSPE}, 55^{\circ} \mathrm{C}$ ). The library was rescreened by use of a random primer-labeled EcoRI fragment of F25 (wash $0.1 \times \mathrm{SSPE}, 65^{\circ} \mathrm{C}$ ) to yield clones $\mathrm{H} 1-\mathrm{H} 9$. Clone $\mathrm{H} 3$ contained a 2.2-kb EcoRI fragment. Sequence was performed by the dideoxy chain-termination method on double-stranded templates. The sequence was determined completely on both strands with overlapping subcloned and exonuclease-shortened templates. In addition, bases $1-1600$ were sequenced completely in parallel with ITP-containing sequencing mixes (U.S. Biochemicals Sequenase kit) to eliminate compression artifacts.

\section{Cu-phenanthroline footprinting}

A fragment of the mouse TTR promoter containing nucleotides -202 to -70 was labeled with ${ }^{32} \mathrm{P}$ on the coding strand. Ten nanograms of this probe was incubated with $10 \mu \mathrm{l}$ of reticulocyte lysate containing the translated product of clone $\mathrm{H} 3$ for 20 min under conditions described previously for gel mobilityshift assays. Probe complexed with protein was separated from free probe on a $5 \%$ native acrylamide gel, and then the entire gel was exposed to DNA cleavage by $\mathrm{Cu}$-phenanthroline, as described by Kuwabara and Sigman (1987). The free and bound probe was located by autoradiography of the treated gel and electroeluted onto DEAE-cellulose. The cleaved probe was eluted from the membrane and analyzed on a $8 \%$ denaturing gel. The dried gel was exposed to X-ray film at $-80^{\circ} \mathrm{C}$ with an intensifying screen.

\section{RNA analysis}

RNA was isolated from rat tissues by the method of Chirgwin et al. (1979). Poly(A)+ RNA was selected by chromatography on oligo(dT) cellulose. Five micrograms of poly $(A)^{+}$RNA from each tissue was separated on a glyoxal-DMSO (dimethyl sulfoxide) $1 \%$ agarose gel and, transferred to nitrocellulose (Schleicher \& Schuell) by electroblotting. Detection of the HNF-3A mRNA was achieved with a probe containing bases $1-910$ of the $\mathrm{H} 3$ clone in $50 \%$ formamide, $5 \times$ SSPE, $5 \times$ Denhardt's solution, and $100 \mu \mathrm{g} / \mathrm{ml}$ salmon sperm DNA at $42^{\circ} \mathrm{C}$. The high-stringency wash was performed in $0.1 \times \mathrm{SSPE} / 0.1 \%$ $\mathrm{SDS}$ at $65^{\circ} \mathrm{C}$ for $10 \mathrm{~min}$. The blot was exposed to X-ray film at $-80^{\circ} \mathrm{C}$ with two intensifying screens for $30 \mathrm{hr}$. RNA loading was evaluated by hybridization of the blot with the rat glyceraldehyde 3-phosphate dehydrogenase probe.

\section{Acknowledgments}

We thank A. Czernik for guidance with HPLC, D. Atherton and the Protein Sequencing Facility for amino acid sequence, $\mathbf{R}$. Doolittle (UCSD) for protein sequence comparisons, W. Chen, C.F. Kuo, K. Xanthopoulos, and M. Ehrlich for help in the RNA analysis, and K.E. Paulson and F. Sladek for helpful discussions. This work was funded by National Institutes of Health (NIH) grant CA16006-16A, NIH training grant (AI07233-12) to R.H.C., and an NIH Endocrine Research training grant (DK073113-01) to E.L.

The publication costs of this article were defrayed in part by payment of page charges. This article must therefore be hereby marked "advertisement" in accordance with 18 USC section 1734 solely to indicate this fact.

\section{Note added in proof}

Sequence data described in this paper have been submitted to the EMBL/GenBank Data Libraries.

\section{References}

Baumhueter, S., D.B. Mendel, P.B. Conley, C.J. Kuo, C. Turk, M.K. Graves, C.A. Edwards, G. Courtois, and G.R. Crabtree. 1990. HNF-1 shares three sequence motifs with the POU domain proteins and is identical to LF-B1 and APF. Genes Dev. 4: 372-379.

Cereghini, S., M. Raymondjean, A.G. Carranca, P. Herbomel, and M. Yaniv. 1987. Factors involved in control of tissuespecific expression of albumin gene. Cell 50: 627-638.

Chirgwin, J.M., A.E. Przybyla, R.J. MacDonald, and W.J. Rutter. 
1979. Isolation of biologically active ribonucleic acid from sources enriched in ribonuclease. Biochemistry 24: 5294 5299.

Costa, R.H., D.R. Grayson, and J.E. Darnell, Ir. 1989. Multiple hepatocyte-specific nuclear factors function in the regulation of the transthyretin and al-antitrypsin genes. Mol. Cell. Biol. 9: 1415-1425.

Costa, R.H., E. Lai, and J.E. Darnell, Jr. 1986. Transcriptional control of the mouse prealbumin (transthyretin) gene: Both promoter sequences and a distinct enhancer are cell specific. Mol. Cell. Biol. 6: 4697-4708.

Costa, R.H., E. Lai, D.R. Grayson, and J.E. Darnell, Jr. 1988. The cell-specific enhancer of the mouse transthyretin (prealbumin) gene binds a common factor at one site and a liverspecific factor(s) at two other sites. Mol. Cell. Biol. 8: $81-90$.

Courtois, G., J.G. Morgau, L.A. Campbell, G. Fourel, and G.R. Crabtree. 1987. Interaction of a liver-specific nuclear factor with the fibrinogen and al-antitrypsin promoters. Science 238: 688-692.

Derman, E., K. Krauter, L. Walling, C. Weinberger, M. Ray, and J.E. Darnell, Jr. 1981. Transcriptional control in the production of liver-specific mRNAs. Cell 23: 731-739.

DeSimone, V., G. Ciliberto, E. Hardon, G. Paonessa, F. Palla, L. Lundberg, and R. Cortese. 1988. Cis- and trans-acting elements responsible for cell-specific expression of the human alpha-1-antitrypsin gene. EMBO I. 6: 2759-2766.

Finney, M. 1990. The homeodomain of the transcription factor LF-B1 has a 21 amino acid loop between helix 2 and helix 3 . Cell 60: 5-6.

Frain, M., G. Swart, P. Monaci, A. Nicosia, S. Stampfli, R. Frank, and R. Cortese. 1989. The liver-specific transcription factor LF-B1 contains a highly diverged homeobox DNA binding domain. Cell 59: 145-157.

Gorski, K., M. Carneiro, and U. Schibler. 1986. Tissue-specific in vitro transcription from the mouse albumin promoter. Cell 47: 767-776.

Herskowitz, I. 1989. A regulatory hierarchy for cell specialization in yeast. Nature 342: 749-757.

Johnson, P.F. 1990. Transcriptional activators in hepatocytes. Cell Growth and Differ. 1: 47-52.

Kadonaga, J. and R. Tjian. 1986. Affinity purification of sequence-specific DNA binding proteins. Proc. Natl. Acad. Sci. 83: 5889-5893.

Kovesdi, I., R. Reichel, and J.R. Nevins. 1986. Identification of a cellular transcription factor involved in E1A trans-activation. Cell 45: 219-228.

Kozak, M. 1986. Point mutations define a sequence flanking the AUG initiator codon that modulates translation by eukaryotic ribosomes. Cell 44: 283-292.

Kuwabara, M.D. and D.S. Sigman. 1987. Footprinting DNAprotein complexes in situ following gel retardation assays using 1,10-phenanthroline-copper ion: E. coli RNA polymerase-lac promoter complexes. Biochemistry 26(23): 7234-7238.

Landschulz, W.H., P.F. Johnson, and S.L. McKnight. 1988. The leucine zipper: A hypothetical structure common to a new class of DNA-binding proteins. Science 240: 1759-1764.

Lathe, R. 1985. Synthetic oligonucleotide probes deduced from amino acid sequence data. J. Mol. Biol. 183: 1-12.

Lichtsteiner, S., J. Wuarin, and U. Schibler. 1987. The interplay of DNA-binding proteins on the promoter of the mouse albumin gene. Cell 51: 963-973.

Melton, D.A., P.A. Krug, M.R. Rebagliatti, T. Maniatis, K. Zinn, and M.R. Green. 1984. Efficient in vitro synthesis of biologically active RNA and RNA hybridization probes from plasmids containing a bacteriophage SP6 promoter. Nucleic Acids Res. 12: 7035-7056.

Monaci, P., A. Nicosia, and R. Cortese. 1988. Two different liver-specific factors stimulate in vitro transcription from the human $\alpha$-1 antitrypsin promoter. EMBO J. 7:20752087.

Nasmyth, K. and D. Shore. 1987. Transcriptional regulation in the yeast life cycle. 237: $1162-1170$.

Powell, D.J., J.M. Friedman, A.J. Oulette, K.S. Krauter, and J.E. Darnell, Jr. 1984. Transcriptional and post-transcriptional control of specific messenger RNAs in adult and embryonic liver. J. Mol. Biol. 179: 21-35.

Reue, K., T. Leff, and J.L. Breslow. 1988. Human apolipoprotein $\mathrm{CIII}$ is regulated by positive and negative cis-activating elements and tissue-specific protein factors. J. Biol. Chem. 263: 6857-6864.

Takahashi, Y., K. Kato, Y. Hayashizaki, T. Wakabayashi, E. Ohtsuka, S. Matsuki, M. Ikehara, and K. Matsubara. 1985. Molecular cloning of the human cholecystokinin gene by use of a synthetic probe containing deoxyinosine. Proc. Natl. Acad. Sci. 82: 1931-1935.

Xanthopoulos, K.G., J. Mirkovitch, T. Decker, C.F. Kuo, and J.E. Darnell, Jr. 1989. Cell-specific transcriptional control of the mouse DNA-binding protein C/EBP. Proc. Natl. Acad. Sci. 86: 4117-4121. 


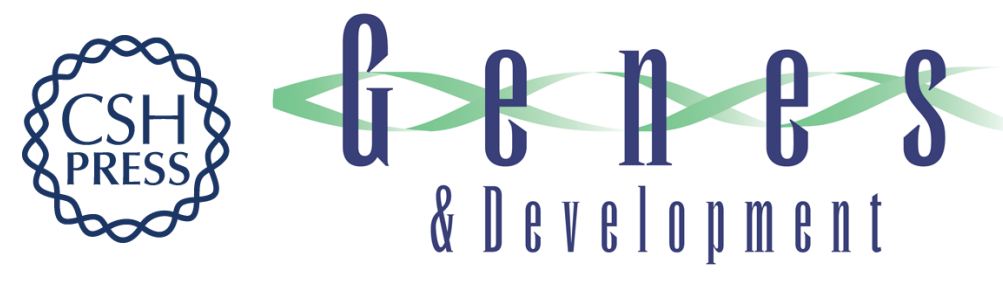

\section{HNF-3A, a hepatocyte-enriched transcription factor of novel structure is regulated transcriptionally.}

E Lai, V R Prezioso, E Smith, et al.

Genes Dev. 1990, 4:

Access the most recent version at doi:10.1101/gad.4.8.1427

References This article cites 27 articles, 10 of which can be accessed free at: http://genesdev.cshlp.org/content/4/8/1427.full.htmI\#ref-list-1

License

Email Alerting

Receive free email alerts when new articles cite this article - sign up in the box at the top Service right corner of the article or click here.

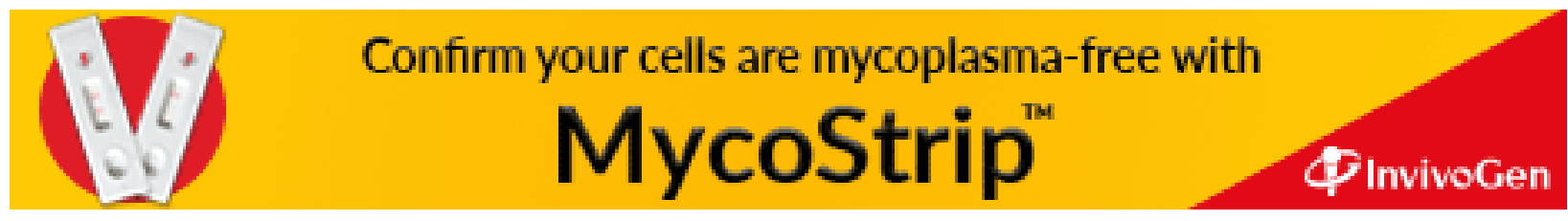

